\title{
Caminhos e Conversas: Homenagem a Ricardo Benzaquen*
}

\author{
Otávio Velho \\ Universidade Federal do Rio de Janeiro (UFRJ), Rio de Janeiro, RJ, Brasil. E-mail: \\ otaviogvelho@gmail.com
}

\begin{abstract}
$\mathrm{R}$ icardo e eu possuímos trajetórias, como pesquisadores, que nunca foram muito próximas, guardadas apenas as exceções do interesse pela questão do cativeiro por ele assinalado (Benzaquen de Araújo, 1994:55) e pela comparação entre Brasil e Rússia; mas, em ambos os casos, a partir de entradas bem diferentes. Sempre estive distante do Pensamento Social Brasileiro e só recentemente, devo confessar, tomei conhecimento de um Manoel Bomfim, cujo livro definitivo ( $\mathrm{O} \mathrm{Bra}$ sil Nação) é contemporâneo de Casa-Grande E Senzala e antecede Raízes do Brasil. Mas afora as relações pessoais, onde, como muitos, me beneficiei da sua amizade e cordialidade, Ricardo e eu tivemos um momento forte de parceria intelectual - e da qual usufruí sobejamente - na relação estabelecida por conta do doutorado e da feitura de sua tese sobre a obra de Gilberto Freyre nos anos 1930. Tese esta cuja defesa, em junho deste ano de 2018, completará 25 anos; o livro tendo sido publicado em setembro do ano seguinte (Benzaquen de Araújo, 1994). Defesa que foi extremamente marcante, até mesmo na história do Museu Nacional. Não só pela qualidade dos debates, mas também devido a um incidente de inundação seguida de curto-circuito que iria redundar em uma interdição do nosso auditório nobre por muito tempo. Na época, Isabel Lustosa escreveu um artigo (O Globo, 25/7/1993) em que
\end{abstract}

\footnotetext{
* Agradeço a Amir Geiger, Ypuan Garcia e Stela Abreu o apoio na preparação deste texto, que originalmente foi apresentado como encerramento do seminário História, Cultura e Amizade: homenagem a Ricardo Benzaquen de Araújo, realizado na Pontifícia Universidade Católica do Rio de Janeiro (PUC-Rio) a 5 e 6 de abril de 2018.
}

DADOS - Revista de Ciências Sociais, Rio de Janeiro, vol. 61, no-2, 2018, pp. 299 a 310. 
Otávio Velho

descreve saborosamente o episódio, dando destaque ao fato de a banca tentar prosseguir os trabalhos como que indiferente ao que ocorria, o que ela comparava com o filme E la nave va de Federico Fellini. E terminava dizendo:

Daqui a 20 anos, se ainda existir universidade no Brasil, se esta universidade ainda deixar que se lecionem ali estas coisas tão inúteis quanto a poesia e a literatura - talvez até mais - e que hoje conhecemos como ciências sociais ou humanas, esta manhã será lembrada.

Diante das ameaças que hoje estamos sofrendo, impressiona a capacidade premonitória da Isabel. E, também, seu artigo serve para recordar que as dificuldades a que ela se refere vêm de longe. Mas como, mal ou bem, e já não tão indiferentes como no filme do Fellini, continuamos aqui e vamos comemorar não mais os 20 , mas os 25 anos da defesa, creio que vale o registro. Ainda mais para mim, particularmente dado o fato de que a feitura dessa tese foi o momento - longo, é verdade, as suas filhas que o digam - mais intenso de encontro intelectual entre mim e Ricardo, o que decidi fazer como preparação para este evento foi simplesmente relê-la (em forma de livro) e tentar transmitir o testemunho de algumas impressões que me ficaram desta releitura feita 25 anos depois. Um pouco óbvia, talvez, esta opção; mas afora o que haja de pessoal nisso, também creio que não se pode negar que esse livrotese tem um lugar especial na produção do Ricardo e merece um destaque.

3) Diria que, para mim, um primeiro ponto a mencionar nesta releitura é a posição do silêncio no livro. E isso provavelmente me chamou a atenção pelo fato de nos agradecimentos Ricardo dizer a meu próprio respeito que a sua gratidão: “... na total impossibilidade de recorrer à música, pode se expressar apenas por intermédio de um relativo, mas eloquente, espero, silêncio" (p. 16). Silêncio, no entanto, que é imediatamente rompido, pois, na página seguinte, que se encontra em face desta, ele me inclui de modo comovente em sua dedicatória do livro. E me inclui juntamente com os seus pais e, in memoriam, nosso amigo comum e antigo decano do Centro de Ciências Sociais da PUC, com quem trabalhamos juntos num generoso projeto de interdisciplinaridade, $\mathrm{o}$ Prof. Isaac Kerstenetsky.

Afora razões evidentemente narcísicas, isso me chama a atenção devido a meu interesse pela chamada teologia negativa ou apofática. Para esta, qualquer afirmação que se faça, demanda correção. Não se trata 
de um silêncio absoluto, portanto, mas de negações sucessivas da qual o silêncio é uma variante forte. Tais negações sucessivas constituem um discurso instável e dinâmico de desdizeres referidos ao não objetificável com um sentido de regressão linguística (em grego, epistrophé, que dá início ao título de um artigo meu justamente agora republicado). Fica, portanto, o convite para que seus leitores releiam este seu Guerra e $p a z$, atentos para essa construção, a que, a meu ver, Ricardo é extremamente fiel de cabo a rabo; e que pode servir, portanto, de chave de leitura interessante de um livro tão festejado e premiado. E quanto a esse último ponto, o da regressão, é interessante desde já assinalar que nos seus últimos capítulos Ricardo mostra que no final de Sobrados E Mucambos há como que uma volta ao passado colonial de Casa-grande $\mathcal{E}$ Senzala. Falarei mais adiante sobre isto, também no espírito da epistrophé.

Mas poderia, então, o próprio Gilberto (para utilizar a expressão familiar do Ricardo) ser entendido assim? Pelo menos é a maneira que ele, Ricardo, escolheu para apresentá-lo. Talvez devido - como sugere Wanderley Guilherme dos Santos na orelha do livro - a "identificações pela via da simpatia de Levy-Bruhl". Ricardo, então, pondo-se como "roteirista, diretor de cena e crítico brechtiano". Em todo o caso, me parece que chamar a atenção para esse ponto pode ajudar a relançar a questão mais geral da linguagem das ciências sociais; pondo de lado, aqui, os constrangimentos e distorções devidos a nossa inserção no chamado sistema de ciência, tecnologia e - agora - inovação. Relançar essa questão tanto para avaliar o discurso dos chamados cientistas sociais, quanto a sua visão e relacionamento com os outros diversos discursos sociais (como, por exemplo, o - ou os - da política). Desse modo se poderia buscar superar não tão eventuais demandas empobrecedoras por "coerência", transformada esta em critério geral de avaliação. E talvez não seja só uma questão de linguagem, mas de procedimentos e epistemologia, e mesmo de ontologia, que esteja em jogo. O inacabamento na forma ensaística de Gilberto ressaltado por Ricardo e outros teria o que nos dizer, então, sobre a própria natureza do real. Mas a isto voltarei adiante.

4) O segundo ponto que gostaria de abordar tem a ver com o que talvez seja a tese principal de Ricardo: a centralidade da noção de antagonismos em equilíbrio para Gilberto. Pelo menos para a obra dos anos 1930 e, sobretudo, para Casa-grande E senzala. Isso é dito e redito por ele de diversas formas, como "convivência tensa, mas equilibrada, de critérios 
Otávio Velho

opostos" (o que caracterizaria antinomias) e a "natureza sincrética do todo". Mas a retomada desse assunto aqui será somente de um ângulo particular, interesseiro, que seria o de se indagar o que isso tem a ver conosco hoje, numa espécie de aggiornamento. Aggiornamento esse associado a um interesse do próprio Gilberto, que, como Ricardo acentua (p. 176), se via como um intervencionista e era contra a "necrofilia", privilegiando a responsabilidade do intelectual com as urgências do seu tempo. E isso de modo semelhante, me parece, ao Nietzsche dos "Usos e abusos da história" das Considerações intempestivas, uma leitura comum a mim e a Ricardo a que voltarei a me referir. Mas esse aggiornamento que me interessa só é possibilitado pela leitura de Ricardo. O que me leva no sentido da simpatia mencionada por Wanderley a falar de um Gilberto-Ricardo. Ou vice-versa.

E para dramatizar um pouco essas urgências do nosso próprio tempo (aliás, pouco necessitadas disso), eu queria correr o risco logo de início de mencionar a candente questão "racial" e da mestiçagem. Neste momento, só para chamar a atenção sinteticamente para as definições a respeito. E aí cabe mencionar que a noção de raça em Gilberto-Ricardo está longe do nosso senso comum; a não consideração desse fato podendo ser fonte de muitos equívocos. Pois, como se recordarão todos os leitores do livro, trata-se de uma definição neolamarckiana de raça a que é posta, a qual acentua "a capacidade de incorporar, transmitir e herdar as características adquiridas" (p. 39), dando origem às chamadas raças artificiais ou históricas.

Em consequência, Gilberto não só (e ao contrário de muitos contemporâneos) tem uma atitude simpática em relação à mestiçagem, como se separa fortemente daqueles que a advogam como estratégia de branqueamento em desespero de causa racista. Nessa separação, aliás, coincidindo com Manoel Bomfim, de quem se distingue em muitos outros pontos. Nas palavras de Ricardo-Gilberto, trata-se do "mestiço como alguém que guarda a indelével lembrança das diferenças presentes na sua gestação". O brasileiro mestiço, portanto, (como antes o próprio português) seria definido por um "luxo de antagonismos" que "recusam-se terminantemente a se desfazer e a se reunir em uma entidade separada, original e indivisível" (p. 44). Assim se caracteriza uma espécie de intraculturalismo biologicamente fundado, que se até poucos anos atrás - mesmo nos tempos de Ricardo - seria considerado ultrapassado pela antropologia, hoje pode retornar à mesa de discussão. Isto a partir de obras como a de Tim Ingold e a sua percepção das habili- 
dades (skills) incorporadas ao organismo humano através da prática e do treinamento em um determinado meio, tornando-se ao mesmo tempo biológicas e culturais (Ingold, 2000). Posição que, como já tive oportunidade de afirmar (Velho, 2018:129-135), retoma de modo original e em novo contexto o sentido geral da obra de Gregory Bateson; a qual, tendo se aproximado do lamarckismo, não só por isso manteve-se por muito tempo como que submersa, disponível apenas para bons pescadores. Pescadores como Gilles Deleuze, por exemplo. E esses seriam a meu ver os sentidos do hibridismo e do sincretismo em GilbertoRicardo, e não o da mestiçagem dissolvente.

Ora, não é preciso dizer que a noção de mestiçagem que predominou não foi a de Gilberto. Tanto assim que muita confusão se fez sobre as ideias dele próprio a respeito. E, em boa parte, a luta do movimento negro contra a ideologia da mestiçagem, muito justa e agudamente, se dirigiu contra a mestiçagem dissolvente. Quanto a isso, gostaria apenas de registrar esta constatação, deixando no ar no momento a questão dos efeitos sobre os debates atuais de um eventual aggiornamento das ideias de Gilberto Freyre - via Ricardo - a respeito.

5)Prosseguindo, gostaria de continuar com o fio dos "antagonismos em equilíbrio". Fio que, podendo ser definidor da mestiçagem híbrida, é também definidor de sociedade "híbrida, simétrica e quase polifônica" (p. 44). E essa sociedade seria por excelência o retrato da sociedade colonial brasileira. Sob domínio patriarcal, bem entendido. Domínio esse extremamente autoritário e violento; caracterização que se perde quando do uso edulcorado da obra de Gilberto, que se tornou hegemônico em todos os lados dos debates a respeito. E tudo isso é bem explicado por Ricardo, inclusive o fato de se tratar de um domínio que não prescindia dos seus opostos, como de modo saliente o dos quilombos, vistos com extrema simpatia por Gilberto. O que é curioso assinalar, sobretudo devido ao retorno forte e inesperado que tem se dado entre nós ultimamente - como verdadeiro escândalo para a consciência moderna - da referência a quilombos e quilombolas, a que voltarei a me referir adiante.

Mas para nossos propósitos intervencionistas, na esteira de GilbertoRicardo e de novo aggiornamento, o que talvez valha mais a pena marcar aqui é o movimento contrário a esse arranjo que se daria a partir do século XIX e que teria como representação do seu ponto de partida a chegada de D. João VI: o processo civilizador de reeuropeização de que a extremamente densa - e, também, evidentemente interessada - des- 
Otávio Velho

crição desse marco inicial feita por Oliveira Lima (Lima, 2006) serve de referência privilegiada, tal como reconhecida por Freyre. Tudo isso enquanto corria mais subterraneamente a transformação dos quilombos em mocambos - mantendo seus traços não patriarcais, comunitários, democráticos - paralela à transformação da casa-grande em sobrado. Esta reeuropeização, se por um lado abala o patriarcalismo violento, leva por outro à transformação das relações entre os grupos sociais de íntimas em excludentes (o que Manoel Bomfim também observara). E também a uma espécie de repressão de nosso lado não ocidental; tema que hoje deveria ganhar renovado interesse no bojo das discussões atuais sobre colonialidade e pós-colonialismo (Velho, 2018:265- 278).

Porém, o que gostaria de frisar aqui, dentro também do que me parece ser o espírito dessa perspectiva freyreana de intervenção, é apenas que, quando hoje, causa espanto aquilo que aparece como uma tendência a um certo purismo por parte do movimento negro, talvez isso pudesse então ser reavaliado. Isso se encarássemos esse outro movimento, o da reeuropeização, este sim, como um movimento de purificação, embora inconcluso; "mais realista do que o rei", como eu costumo dizer (Velho, 2007). Mas violento, por sua vez, na medida em que substituiu (também parcialmente) o excesso, a hybris do patriarcalismo, por uma nova hybris: a da Ordem. Talvez bem representada essa nova hybris, ainda no século XIX - se me permitem a sugestão de um exemplo forte-, pelo suposto massacre dos Lanceiros Negros no final da Revolução dos Farrapos, via um conluio entre a liderança farroupilha e a imperial. Suposição que, descartada até recentemente como versão não comprovada, hoje vai se transformando em convicção política, numa espécie de redescoberta e resgate que possivelmente constitui apenas uma antecipação do muito a desencavar em nossa história que ainda está por vir. O cientista político norte-americano Mark Lilla tem sugerido (e fala sobre isso em entrevista à Folha de S. Paulo de 23 de março próximo passado) que o Ku Klux Kan foi o primeiro grupo identitário norte-americano. Pois quem sabe, nesse sentido, essa reeuropeização não deveria ser encarada de forma semelhante, podendo ser vista como tão ou mais violenta que a sua congênere? Embora tudo isso bem disfarçado pelo que Ricardo (e outros) considera ser a sua natureza de processo civilizador; mas, no caso, sob a já referida hybris da Ordem, que sempre teve os seus condestáveis.

Gilberto buscou pensar um retorno desejável - bem típico de uma epistrophé - a um equilíbrio de antagonismos, agora despido do patriarcalismo e da hybris. Isto por via da permanência da tradição popular dos 
quilombos combinada com o letramento dos mulatos. Ocorre que Ricardo, nesse momento estratégico da sua argumentação, se aparta e acata o fato de que há críticas fundadas à consistência desta solução proposta por Freyre. Por exemplo, as críticas da parte de Luiz Costa Lima. Não sendo especialista, não tenho condições de enfrentar essa discussão. Mas gostaria neste ponto de ousar propor uma alternativa tardia para esse impasse. Isto em forma de indagação sobre se hoje não haveria condições sociais e políticas novas que permitiriam uma solução não retórica indisponível e impensável nos tempos de Freyre, e mesmo nos tempos de Ricardo. Condições estas decorrentes da pujança e da capacidade de mobilização reveladas pelo movimento negro nos últimos anos. E isso juntamente com as do movimento feminista, bem mais efetivo em sua capacidade transformadora do que as sinhás dos sobrados, em que Freyre depositava esperanças de realização de um trabalho de reintegração cultural por via da culinária que hoje soam um tanto ingênuas.

Tudo isso, a meu ver, em tempos de impasse e de crise como os que estamos vivendo, representando um fato novo da maior importância, capaz de sacudir o conjunto da sociedade e todos os atores políticos estabelecidos de um modo que vai muito além do que se possa antever. Não sendo, ainda, de se desprezar, por outro lado, que, mesmo entre os mais fortes defensores de uma política das identidades que no futuro poderá ser vista como uma resposta necessária diante do purismo re-europeizador, mas a demandar desdobramentos, já surgem vozes como a da filósofa Nancy Fraser e a do boliviano também filósofo Rafael Bautista - alertando para os riscos de uma fragmentação sem fim. Riscos, sobretudo, para a construção e potencialização de um espaço público, o que parece apontar para a necessidade de um momento seguinte pós-identitário, por assim dizer. Inclusive para enfrentar melhor o espectro da hybris (tal como Freyre idealizava pudesse ser feito pelo mucambo), tão contaminadora por si mesma; e que, ao mesmo tempo, não pode ser desprezada, até por se tratar de instrumento de resistência eficaz e legítimo quando brandido pelos de baixo. Enfrentamento, no entanto, onde, por sua vez, a concepção freyreana - e não só freyreana, é de se supor - de uma mestiçagem híbrida, não dissolvente, pode ainda vir a ser acionada. Acionada, porém, somente uma vez superado - quem sabe, um dia? - o trauma da compreensão profunda tardiamente rediviva da noção original de mulato(a) e de suas atualizações. Superação possivelmente já encaminhada hoje, explorando trilha diversa com a distinção marcada entre negro(a) e preto(a). 


\section{Otávio Velho}

Nessa passagem a um momento pós-identitário, no entanto, não é de se desprezar igualmente a possibilidade de surgimento de uma disputa dura com inesperados movimentos de reeuropeização, agora de natureza fortemente reativa; cheios de hybris e mais ou menos camuflados enquanto tais. Movimentos alertando, igualmente, para os ditos riscos da fragmentação. Porém, nesta versão, não a demandar uma resposta política elaborada a esses riscos, e sim um descarte liminar em nome de uma suposta naturalidade original ameaçada; essa parecendo ser uma concepção bem mais simples, por exemplo, que o próprio antagonismos em equilíbrio freyreano. Em reprise, portanto, parece tratar-se de uma versão paradoxal, anacrônica, quiçá perversa e farsante da reeuropeização. Mas que não deixa por isso de ser autêntica ao remeter a momentos sinistros que a história registrou e continua a registrar. E isso com cores fortes, participando, portanto, do mesmo espelhamento múltiplo que leva até a que se fale, por outro lado, em abrasileiramento ou latinoamericanização da Europa. Movimentos sinistros, é bom frisar, aos quais a "questão racial" nunca foi alheia, muito pelo contrário. Assim, é o caso de se perguntar se estamos ainda diante de um processo civilizador. Ou, alternativamente, perguntar quem será agora, nessas circunstâncias, o agente de um processo civilizador.

Mas isso são ainda, em parte pelo menos, especulações. Fica, porém, esse conjunto de sugestões, algumas das quais - para continuar com atualidades - talvez pudessem ser ilustradas por duas estrofes de um samba-enredo do carnaval deste ano de 2018 que causou bastante polêmica e que eu sugeriria ser direta ou indiretamente de inspiração freyreana: o do Paraíso do Tuiuti. A transcrição da primeira estrofe, creio que, a esta altura, não demanda maiores justificativas:

Não sou escravo de nenhum senhor

Meu paraíso é meu bastião

Meu Tuiuti, o quilombo da favela

É sentinela na libertação.

Fica o registro do "quilombo da favela". E a outra estrofe tem a ver com o que falarei a seguir para encerrar esta apresentação:

E assim, quando a lei foi assinada

Uma lua atordoada assistiu fogos no céu

Áurea feito o ouro da bandeira

Fui rezar na cachoeira contra a bondade cruel. 
E aí eu chamaria a atenção exatamente para o final da estrofe: a referência à "bondade cruel".

6) Encerrando, portanto, gostaria de retomar a questão inicial do modo de exposição e argumentação de Ricardo e de Gilberto. E assim como comecei me referindo aos agradecimentos iniciais de Ricardo, agora me referiria a suas últimas páginas e, mais especificamente, a sua última página. Ali ele esclarece e realça a ligação entre a construção do texto em Gilberto e a ambiguidade, o excesso e a instabilidade que "caracterizavam a sociabilidade da casa-grande" (p. 208), o lócus por excelência dos antagonismos em equilíbrio e, creio, criadouro de manifestações paradoxais, que, se transformando, se prolongam. E essa ligação é então definida de modo um tanto surpreendente como sendo resultado da transferência para o texto de parte das características dessa sociabilidade por via da oralidade, o que permite "... que ele arme um raciocínio francamente paradoxal, fazendo com que a cada avaliação positiva possa se suceder uma crítica e vice-versa, em um ziguezague que acaba por dar um caráter antinômico a sua argumentação" (p. 208, ênfases no original); o que de novo poderia nos remeter a Gregory Bateson e, no caso, a sua noção de duplo vínculo, tal como já tratei alhures (Velho, 2018:191-212). Mas, em todo o caso, eis aí um raciocínio realista sofisticado e original, de certa forma prefigurado quando da menção às limitações da linguagem indicadas pela posição do silêncio e dos desdizeres em Guerra e paz; capaz até de esse raciocínio realista fazer repensar em seus desdobramentos o poder absoluto supostamente determinante das narrativas. Poder esse substituído, também, como que por laços de simpatia, não exclusivamente entre humanos. E caberia, aqui, um parênteses para chamar a atenção de que a mesma palavra que Ricardo utiliza para se referir a Gilberto, ziguezague, muito significativamente serve para Marcelo Jasmim referir-se a ele próprio, Ricardo, no título da bela homenagem que lhe prestou em artigo publicado na revista Intercessões: "Ziguezagueando com Ricardo Benzaquen no Departamento de História da PUC-Rio" (Jasmim, 2017). Mais uma vez isto parece confirmar os laços de simpatia presentes de diversas formas; laços, aliás, certamente não estranhos à dignidade do tema da amizade tal como proposto para este seminário.

Mas, prosseguindo nesse fio e para terminar, logo a seguir a esse trecho de Ricardo que acabo de citar e antes de se referir à antinomia como "a defesa simultânea de argumentos que se opõem", ele em nota diz acreditar que o texto fundamental para essa discussão é o do “Usos e abu-

DADOS - Revista de Ciências Sociais, Rio de Janeiro, vol. 61, nº 2, 2018 


\section{Otávio Velho}

sos da história" de Nietzsche em suas Considerações intempestivas (variando as traduções desses títulos conforme a edição). E a propósito disso e de uma aproximação com Weber e sua utilização de argumento de caráter antinômico, refere-se a um texto meu publicado em 1985, não por acaso intitulado "Considerações intempestivas sobre Nietzsche e Weber". E não por acaso, de novo, mas também por coincidência, neste momento presente está sendo lançada uma nova coletânea minha intitulada - de modo que me parece expressivo para toda essa discussão - Antinomias do real (Velho, 2018), onde, aliás, no posfácio, falo em guerra "não só de narrativas" para caracterizar o momento que atravessamos. O título não foi escolhido por mim, mas pelo organizador do livro, Amir Geiger, a partir da sua leitura arguta do conjunto de meus textos. Isto para mim é muito esclarecedor sobre as reais afinidades existentes entre mim e Ricardo, esse esplêndido e querido amigo. O Ricardo mestre das intervenções suaves, mas de efeitos que se prolongam, se transformam e se desdobram no tempo, distantes das glórias fugazes. E por ter tido a possibilidade de, ao homenageá-lo, compreender isto melhor, agradeço sinceramente aos organizadores a oportunidade de participar deste seminário.

Submetido em 3 fevereiro de 2018 Aprovado em 10 maio de 2018 


\section{Caminhos e Conversas: Homenagem a Ricardo Benzaquen}

\section{REFERÊNCIAS BIBLIOGRÁFICAS}

BENZAQUEN DE ARAÚJO, Ricardo. (1994), Guerra e Paz: Casa-grande E Senzala e a Obra de Gilberto Freyre nos Anos 30. Rio de Janeiro, Editora 34.

INGOLD, Tim. (2000), The Perception of the Environment: Essays in Livelihood, Dwelling and Skill. London, Routledge.

JASMIM, Marcelo. (2017), “Ziguezagueando com Ricardo Benzaquen no Departamento de História da PUC-Rio". Intercessões, ano 19, no 1, pp. 20-25.

LIMA, Oliveira. (2006)[1908], Dom João VI no Brasil. Rio de Janeiro, Topbooks.

VELHO, Otávio. (2007), Mais Realistas do que o Rei: Ocidentalismo, Religião e Modernidades Alternativas. Rio de Janeiro, Topbooks.

(2018), Antinomias do real. Rio de Janeiro, Editora UFRJ, org. Amir Geiger. 


\section{Otávio Velho}

\section{RESUMO}

Caminhos e conversas: homenagem a Ricardo Benzaquen

Neste artigo o autor estabelece um diálogo teórico póstumo com Ricardo Benzaquen, um dos principais estudiosos do pensamento social brasileiro e de teorias sociais. Desta forma, o autor presta uma homenagem não apenas ao intelectual mas sobretudo a obra de Benzaquen.

Palavras chave: Ricardo Benzaquen, pensamento social brasileiro, teoria social, homenagem

\section{ABSTRACT}

Paths and conversations: homage to Ricardo Benzaquen

In this article the author establishes a posthumous theoretical dialogue with Ricardo Benzaquen, one of the leading scholars of Brazilian social thought and social theories. In this way, the author pays tribute not only to the intellectual but especially the work of Benzaquen.

Keywords: Ricardo Benzaquen, Brazilian social thought, social theory, homage

\section{RESUMEN}

Caminos y conversaciones: homenaje a Ricardo Benzaquen

En este artículo el autor establece un diálogo teórico póstumo con Ricardo Benzaquen, uno de los principales estudiosos del pensamiento social brasileño y de teorías sociales. De esta forma, el autor rinde homenaje no sólo al intelectual, sino sobre todo a la obra de Benzaquen.

Palabras clave: Ricardo Benzaquen, pensamiento social brasileño, teoría social, homenaje 